Original article

\title{
Psychometric properties of the Persian version of Whiteley Index
}

\author{
Mahin Eslami, Habibeh Ahmadipour, Faezeh Bagheri \\ Kerman University of Medical Sciences, Kerman, Iran
}

Received 21 March 2017, Accepted 4 April 2017

(C) 2017, Eslami M., Ahmadipour H., Bagheri F.

(C) 2017, Russian Open Medical Journal

Abstract: Background - Health anexity affects the doctor-patient relationship and also causes unnecessary further procedures. Therefore, early diagnosis of it with a valid instrument is very important.

Objectives - The aim of this study was to evaluate psychometric properties of the Persian version of 14-item Whiteley Index.

Material and Methods - This research was a cross sectional study carried out in the medical school of Kerman University of Medical Sciences. Our statistical population included all medical students who were studying in clerkship and internship in 2016. Data collected by using the Persian version of 14-item Whiteley Index and general health questionnaire. The reliability of the questionnaire determined using Cronbach's alpha and test-retest. The construct validity evaluated by principal component analysis and confirmatory factor analysis.

Results - Three hundred and ten medical students participated. The reliability of Whiteley Index was 0.88 and 0.82 using Cronbach's alpha and intra class correlation coefficients. In the principal component analysis, two factors were extracted with the total amount of $50.4 \%$ explained variance. In confirmatory factor analysis the models had acceptable goodness of fit indices.

Conclusion - Persian version of 14-item Whiteley Index can be used as a reliable and valid instrument for assessing Health anexity among Iranian young population.

Keywords: health anxiety, hypochondriasis, reliability, validity

Cite as Eslami M, Ahmadipour H, Bagheri F. Psychometric properties of the Persian version of Whiteley Index. Russian Open Medical Journal 2017; 6: e0307.

Correspondence to Habibeh Ahmadipour. Phone: 03433257313. Fax: 03433257671. E-mail: ahmadipour@kmu.ac.ir.

\section{Introduction}

Hypochondriasis is a mental disorder characterized by belief in having a serious illness and thinking anxiously about it [1]. Although the patient reports symptoms, no abnormal physical finding can be found in most cases [2]. "According to DSM-5, patients previously diagnosed with hypochondriasis are diagnosed with either somatic symptom disorder (if physical complaints are prominent) or illness anxiety disorder (if physical complaints are minimal or nonexistent)" [3]. The prevalence of hypochondriasis, in various studies, has been reported between 3.0-6.3\%. Symptoms of health anxiety reported 5-30 and 2-13 percent in the primary care and general population, respectively [3]. The disorder affects interpersonal relationships, especially, the doctor-patient relationship and also has economic burden due to unnecessary further procedures. Despite these negative effects, often, it is not diagnosed [2].

Different instruments have been developed to screenhypochondriasis and health anxiety $[2,4]$. Whitely Index (WI), Illness Attitude Scales, Somatosensory Amplification Scale are examples of these tools [4]. A 14-item version of the Whiteley Index has been developed by Pilowsky and has been usedin several studies in original or modified versions, in different population, and in clinical settings [5]. In this tool, responses are dichotomous with total score ranges from zero to fourteen [6]. Also, a five-point scale ( $1=$ "Not at all" and $5=$ "Extremely") has been used in some literatures [7]. Psychometric properties of 14- item Whiteley Index have been evaluated in different studies. Some of them found a three-factor solution including disease phobia, bodilypreoccupation, and diseaseconviction while others revealed single factor with good internal consistency $[2,6,7]$.

It seems that according to the new definition of disease, the instrument evaluated mainly illness anxiety rather than somatic symptom disorder. Furthermore, it has been revealed that Likertscale has better psychometric properties [8]. So, we investigated psychometric properties of the Persian version of Likert-scale 14item Whiteley Index.

\section{Material and Methods}

\section{Design}

This research was a cross sectional study carried out in the medical school of Kerman University of Medical Sciences (Kerman, Iran). Our statistical population included all medical students who were studying in clerkship and internship in 2016. The participants selected by census method.

The study was approved by the research review board at Kerman University of Medical Sciences (Kerman, Iran).

The questionnaires were completed anonymously and voluntarily. The participants were assured that the data would be used only for research purposes. The questionnaires were distributed and completed either before or after weekly formal classes. Ten minutes required to complete the questionnaire. 
Table 1. Exploratory factor loading of Whiteley Index

Do you often worry about the possibility that
you have got a serious illness?

FL, factor loading.

Table 2. Comparison of the goodness of fit indices in one-factor and twofactor models

\begin{tabular}{lccccccc}
\hline Model & $\chi^{2} / d f$ & SRMR & $R M S E A(C 195 \%)$ & GFI & AGFI & NFI & CFI \\
\hline OFM & $297 / 77$ & 0.06 & $0.11(0.09-0.12)$ & 0.86 & 0.81 & 0.92 & 0.94 \\
TFM & $190 / 74$ & 0.05 & $0.07(0.06-0.08)$ & 0.91 & 0.88 & 0.95 & 0.97
\end{tabular}

$\chi^{2}$, Chi-square; df, degree of freedom; OFM, one-factor model; TFM, twofactor model; SRMR, standardized root mean square residual; RMSEA, root mean square error approximation; GFI, goodness of fit Index; AGFI, adjusted goodness of fit index; $\mathrm{NFI}$, normed foi index; $\mathrm{CFI}$, comparative fit index.

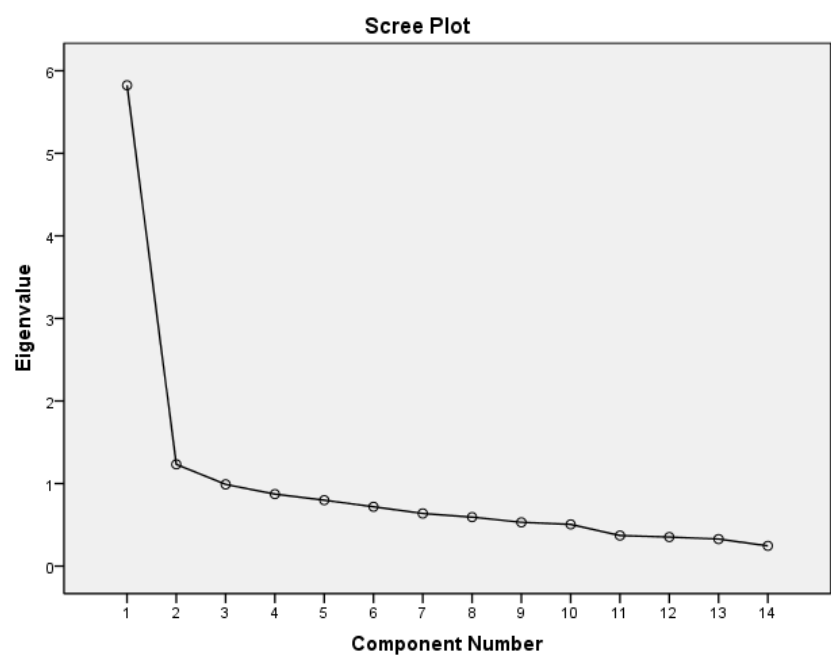

Figure 1. Scree plot in principle component analysis of Whiteley Index

\section{Subjects}

A total of 310 medical students participated in the study (participation rate: $76.1 \%$ ). Their mean age was $24.1 \pm 1.1$ years with minimum and maximum of 21 and 28 years, respectively. One hundred and eighty six (60\%) participants were studying at clerkship and 233 (75\%) were single.

\section{Whiteley Index (WI)}

The original version of WI was translated into Persian by two professors who were highly qualified in English. By comparing the text of two translations, a Persian version was prepared. This Persian version was back translated into English by a translator who was not familiar with the content of the original questionnaire.

\section{General Health Questionnaire-28 (GHQ28)}

The Persian version of General Health Questionnaire (GHQ28) was used. The validity and reliability of this version was confirmed in previous studies [9]. The four point scale (0-3) scoring system was used in this study with a total possible score ranging from 0 to 84 [10].

\section{Statistics analysis}

Data analyzed by SPSS version 19 and Lisrel 8.8. Face and content validity of the questionnaire was confirmed by a number of medical experts. The reliability of the questionnaire determined in a pilot study using internal consistency (Alfa Cronbach) and testretest. Exploratory principal component analysis conducted on the items of using Kaiser Criterion and scree plot. Confirmatory factor analysis also employed.

\section{Results}

Internal consistency of WI and GHQ28 by the Cronbach's alpha was determined 0.88 and 0.82 , respectively. In test-retest reliability, intraclass correlation of WI was calculated 0.82 . There was a statistical significant correlation between the scores of the $\mathrm{WI}$ and GHQ28 ( $r=0.4, \mathrm{P}=0.001)$.

In exploratory factor analysis, Kaiser-Meyer-Olkin Measure of Sampling Adequacy was 0.9 and Bartlett's Test of sphericity was statistically significant $\left(P=0.001, \chi^{2}=1451.9, d f=91\right)$. These results indicated propercorrelation of factors, adequacy of sampling and the justifiability of factor analysis.

In the principal component analysis, two factors with eigenvalues greater than 1.00 are extracted (Table 1 and Figure 1).

The total amount of variance explained by these factors was $50.4 \%$ ( $41.6 \%$ and $8.8 \%$ for first and second factor, respectively). First factor included items 1, 2, 3, 4, 5, and other items placed in second factor.

The Cronbach's alpha coefficient was 0.75 for first factor and 0.85 for second factor. Confirmatory factor analysis was used to compare the goodness of fit indices in one-factor and two-factor models (Table 2).

\section{Discussion}

Our study evaluated psychometric characteristics of the Persian version of 14-item WI in a sample of medical students in Kerman University of Medical Sciences (Kerman, Iran). 
Total reliability of 14 -item WI was 0.88 using Cronbach's alpha coefficient indicating good internal consistency $[11,12]$ that was compatible with similar studies. Speckens et al. revealed good to satisfactory internal consistency for the instrument. They found the Cronbach's alpha of the total WI was $0.76,0.80$ and 0.78 in general population, medical outpatients and general practice setting, respectively [4].

Conradtet al. reported the alpha consistency coefficient as 0.68 for the WI-7 [2]. Schulte-van Maaren et al. found Cronbach's Alpha as 0.90 and sensitivity/specificity $0.95 / 0.93$ for 14 -item WI [6]. Also, in present study, intraclass correlation of WI was calculated as 0.78 that was good [11] but lower than similar studies. Speckens and colleagues found intraclass correlation as 0.9 [4] and another study revealed high test-retest reliability of the instrument [8].

In our study, Kaiser-Meyer-Olkin measure and Bartlett's test of sphericity revealed proper correlation of factors, adequacy of sampling and the justifiability of factor analysis [12]. Principal component analysis confirmed the presence of two factors that are inconsistent with other studies. However, Speckens found a one factor solution in all three study populations [4]. Pilowsky et alextracted three factors by exploratory principal component analysis, interpreted as disease phobia, bodily preoccupation, and disease conviction [2]. Other studies also proposed three factor solutions for this instrument but factors are not exactly the present factors in the original questionnaire developed by Pilowsky $[2,13,14]$. The discrepancy between the results of present study with others may be derived from differences in cultural backgrounds, dissimilar studied samples and diversity in methods for statistical analysis.

In addition, we conducted confirmatory factor analysis for one and two factor solution of the instrument. According to this analysis, both models had acceptable goodness of fit indices while, two-factor model had a slightly better indices. So, according to the results of this study the Persian version of 14-item WI can be used as a reliable and valid instrument for assessing hypochondriasis among Iranian young population.

\section{Conclusion}

The Persian version of 14 -item WI had good reliability and validity.

\section{Acknowledgments}

The authors express their gratitude to Kerman University of Medical Sciences (Kerman, Iran) for supporting the study.

\section{Conflict of interest}

The authors have no conflict of interest.

\section{References}

1. Sadock BJ, Sadock VA. Comprehensive textbook of psychiatry; 8th ed. Philadelphia: Lippincott, Williams and Wilkins, 2005; $1810 \mathrm{p}$.

2. Conradt M, Cavanagh $M$, Franklin J, Rief W. Dimensionality of the Whiteley Index: Assessment of hypochondriasis in an Australian sample of primary care patients. J Psychosom Res 2006; 60(2): 137143. https://doi.org/10.1016/j.jpsychores.2005.07.003.

3. Levenson JL. Illness anxiety disorder: epidemiology, clinical presentation, assessment, and diagnosis [updated May 26, 2017]. https://www.uptodate.com/contents/illness-anxiety-disorderepidemiology-clinical-presentation-assessment-and-diagnosis.

4. Speckens $A M$, Spinhoven $P$, Sloekers $P$, Bolk JH, Hemert AM. A validation study of the Whitely index, the illness attitude scales and the somatosensory amplification scale in general population and general practice patients. J Psychosom Res 1996; 40(1): 95-104. http://dx.doi.org/10.1016/0022-3999(95)00561-7.

5. Fink $P$, Ewald $H$, Jensen J, Sørensen L, Engberg $M$, Holm M, MunkJørgensen $\mathrm{P}$. Screening for somatization and hypochondriasis in primary care and neurological in patients: a seven-item scale for hypochondriasis and somatization. J Psychosom Res 1999; 46(3): 261273. http://dx.doi.org/10.1016/S0022-3999(98)00092-0.

6. Schulte-van Maaren YW, Giltay EJ, van Hemert AM, Zitman FG, de Waal MW, Van Rood YR, Carlier IV. Reference values for the Body Image Concern Inventory $(\mathrm{BICl})$, the Whitely Index (WI), and the Checklist Individual Strength (CIS-20R): The Leiden Routine Outcome Monitoring Study. J Affec Disord 2014; 164: 82-89. https://doi.org/10.1016/j.jad.2014.03.013.

7. Noyes RJ , Stuart SP, Langbehn DR, Happel RL, Longley SL, Muller BA, Yagla SJ. Test of an interpersonal model of hypochondriasis. Psychosom Med 2003; 65(2): 292-300. https://doi.org/10.1097/01.PSY.0000058377.50240.64.

8. Hedman E, Lekander M, Ljótsson B, Lindefors $N$, Rück C, Andersson $\mathrm{G}$, et al. Optimal cut-off points on the Health Anxiety Inventory, Illness Attitude Scales and Whiteley Index to identify severe health anxiety. PLoS One 2015; 10(4): e0123412. https://doi.org/101371/journalpone0123412.

9. Noorbala AA, Bagheri Yazdi SA, Mohammad K. The validation of General Health Questionnaire-28 as a psychiatric screening tool. Hakim Res J 2008; 11(4): 47-53. Persian. http://hakim.hbi.ir/article-1464-en.html.

10. Sterling M. General Health Questionnaire - 28 (GHQ-28). Journal of Physiotherapy 2011; 57(4): 259. http://dx.doi.org/10.1016/S18369553(11)70060-1.

11. Nakhaei N. Questinnaire design and analysis. Kerman: Gera, 2013. Persian

12. Badiyepeymaye Jahromi Z, Keshavarzi S, Jahanbin I. Determination of the reliability and validity of the Persian version of nurses' self-concept questionnaire (NSCQ). Nursing Education Journal 2013; 2(4): 63-71. Persian. http://jne.ir/article-1-275-en.html.

13. Rief W, Hiller W, Geissner E, Fichter MM. Hypochondrie: Erfassung und erste klinische Ergebnisse. Klin Psychol Forsch Prax 1994; 23(1): 34-42. German

14. Hiller W, Rief W, Fichter MM. Dimensional and categorical approaches to hypochondriasis. Psychol Med 2002; 32(4): 707-718. https://www.ncbi.nlm.nih.gov/pubmed/12102385.

\section{Authors:}

Mahin Eslami - Associate Professor of Child Psychiatry, Neurology Research Center, School of Medicine, Kerman University of Medical Sciences, Kerman, Iran.

Habibeh Ahmadipour - Associate Professor of Community Medicine, Social Determinants of Health Research Center, Institute for Futures Studies in Health, Kerman University of Medical Sciences, Kerman, Iran. http://orcid.org/0000-0001-5880-451X.

Faezeh Bagheri - MD, School of Medicine, Kerman University of Medical Sciences, Kerman, Iran. http://orcid.org/0000-0002-2247-2661. 